\title{
5
}

\section{Governing in common - integration and effectiveness in ecological governance}

Specialisation or integration. Organising principles of ecological governance for sustainability

From environment to sustainable development; the quest for effectiveness and integration

The first decades of environmental policy in Sweden were characterised by an amalgamation of different governmental units dealing with aspects of the environmental issue into a recognisable sectoral policy domain. This was how SEPA came to be a specialised agency, whose mission was to prevent or mitigate the effects on the environment of different socio-economic activities. Top priorities were to clean up and prevent pollution, and help in creating a system of constraints against undue exploitation of valuable natural environments. The guiding normative principle was one of 'balancing interests'; the environment was seen as one societal interest that should be weighted against others, and could sometimes lose out in the process (see Lundqvist 1971). Within this normative and administrative context, the strategy was for some time remarkably successful (Lundqvist 1995).

However, with growing evidence of the cross-sectoral and cross-temporal character of ecological and socio-economic relationships, as manifested in the 'diffuse source' problems of pollution, the need for more integrated modes of governance was increasingly realised in the 1980s. An important contribution no doubt came from the development of new ideas and thoughts at the international level. The Brundtland Commission's report explicitly stated that the 'standard agenda' of environmental 
policy focusing on environmental effects would no longer do; concentration must from now on be on the policies that cause these effects. In the words of the Commission,

Sustainable development objectives should be incorporated in the terms of reference of those cabinet and legislative committees dealing with national economic policy and planning as well as those dealing with key sectoral and international policies. As an extension of this, the major central economic and sectoral agencies of governments should now be made directly responsible and fully accountable for ensuring that their policies, programmes, and budgets support development that is ecologically as well as economically sustainable. (WCED 1987:314)

The Commission's words point towards two different but interrelated problems of ecological governance. One problem concerns effectiveness and efficiency. Ecologically rational governance for sustainable development is then seen as a conscious use of strategies to achieve ambitious ecological objectives through policy integration, striving for 'a lasting, systematic and innovative opening of the non-environmental policies towards ecological policies in the comprehensive sense' (Knoepfel 1995:198). The problem here is how to instil ecological concerns into the workings of traditionally non-environmental sectoral policies and agencies to achieve not only effective goal achievement, but also to do so in the most cost-effective way.

The other problem is related to the strength of ecological concerns in such policy integration. Where the effectiveness/efficiency problem concerns how to integrate and how to make that integration work in a cost-effective way, the problem of strength relates to how much weight environmental or ecological concerns should carry in the decision-making process within and across different policy fields. On the one hand, if objectives of sustainability are put above other concerns in the hierarchy of objectives of political governance, then liberal democratic concerns for individual autonomy and equality of opportunity may be jeopardised. On the other hand, if objectives of ecological sustainability continue to be dealt with in the way environmental concerns were historically 'balanced' in Sweden's environmental policy, the prospects for sustainable development are dimmed. 
Ecologically sustainable development as an integrative criterion for rational governance

What was just said about effectiveness/efficiency and strength indicates that policy integration has organisational as well as normative aspects. The organisational aspect of environmental policy integration could be taken to mean how environmental concerns are 'integrated into' different sectoral policies. In this respect integration includes, among other things,

- access for ecological governance to policy instruments used in sectoral policies;

- build-up and/or strengthening of institutional structures to bring attention to issues of sustainability and provide arenas for solution of conflicts;

- conscious strategies and means of monitoring ecological performance in terms of resources used and results achieved in relation to the sector's overarching objectives (see Knoepfel 1995).

Integration then becomes, in effect, similar to problems of coherence, co-ordination, conflict resolution, and effective performance found within most policy areas. But when is a policy fully integrated? It has been suggested that for this to be the case, three criteria should be satisfied, i.e., comprehensiveness, consistency and aggregation. The first refers to the inclusiveness in terms of space, time, actors and issues. Aggregation means that policies and policy measures are evaluated from some overarching criterion or principle, and consistency connotes that the components of the policy are in agreement. An integrated policy is thus one where 'all significant consequences of policy decisions are recognised as decision premises, where policy options are evaluated on the basis of their effects on some aggregate measure of utility, and where the different policy elements are in accord with each other' (Underdal, 1980:162).

The most important aspect of Underdal's definition is that of aggregation. It directs attention to the issue of what relative weights should be given to different objectives or standards existing alongside each other in policy-making both intra- and inter-sectorally. Noting that earlier discussions on environmental policy integration - (such as Collier 1994; Liberatore 1997) assume a 'balance' or a possible resolution of goal conflicts 
among sectoral objectives, Lafferty argues that the core aim of such integration is, at the very least, to avoid situations where environmental objectives become subsidiary. It also means - in the broader purview of sustainable development - to ensure that they become principal or overarching societal objectives. This is, he contends, 'arguably the essential difference between environmental policy integration and policy integration in general' (Lafferty 2001:10). In his view, environmental policy integration implies:

- the incorporation of environmental objectives into all stages of policymaking in non-environmental policy sectors,

- a specific recognition of this goal as a guiding principle for the planning and execution of policy;

- an attempt to aggregate presumed environmental consequences into an overall evaluation of policy, and

- a commitment to minimise contradictions between environmental and sectoral policies by giving priority to the former over the latter (Lafferty 2001:10).

Lafferty's definition addresses the normative issue of prioritisation of environmental concerns. It pictures environmental objectives as fundamental premises throughout all policy processes. Furthermore, it breaks with the earlier assumptions of 'balancing' and 'conflict solvability' by explicitly making environmental concerns central in all policymaking. This is, argues Lafferty, motivated by the increasing recognition that there are environmental/ecological objectives 'which simply cannot be "balanced" with political goals that challenge the basis' for lifesupport systems (Lafferty 2001:11).

However, if such infusion of, and prerogative for, environmental concerns in all policy were taken to imply that environmental objectives should always come before other objectives of societal governance, then democratic norms and the value of autonomy would seem to be endangered. In particular, the effectiveness/efficiency argument for integration may find such norms and values burdensome. How the balance between democracy and autonomy on the one hand and an ecologically rational pursuit of sustainability on the other should be achieved is thus a most crucial issue for ecological governance. 
Common criteria for operational and effective integration

The perspective of ecologically rational governance used here is particularly concerned with the institutions, processes and policies of government. Historically, governments have developed patterns of differentiated sectoral responsibility. To elaborate the concept of environmental policy integration into operational criteria for integrated ecological governance, one should thus relate it to the structures and processes of government.

Effective integration means that environmental concerns are in fact taken into account at all stages and levels of policy- and decision-making with as little sacrifice as possible in terms of time, money and human input. To achieve this ecological efficiency in a sector of government makes it necessary for the responsible bodies to identify the sector's environmental problems as well as the key actors and how to relate to them. Furthermore, there should be a strategy for achieving sectoral environmental objectives with target levels and dates, as well as plans for sectoral environmental action, linked to the sector's budgeted resources. To enable judgements about impacts there should be arrangements and procedures through which the actual achievement of environmental/ecological objectives can be monitored and measured. One should note, however, that this type of integration could still be analysed as intra-sectoral. 'Effective environmental policy can be realised only if infrastructure policies become "ecologised"' (Knoepfel 1995:214).

However, the extent to which sectoral agencies have been internally ecologised 'does not presuppose an overarching primacy for environmental goals at the cabinet level' (see Lafferty 2001:12). What one may call inter-sectoral integration comes about only if and when the ecological concerns are given a specific weight in relation to other sectoral objectives, all the way from equal to 'more equal than others'. The analysis thus concerns what is the 'basic mandate for environmental privilege', and what are the measures for driving this home within and above all - across the different sectors. Central government - read the Cabinet - has many regulatory, economic and informative instruments to steer the sectoral agencies towards a preferred balance among economic, social and ecological aspects of sustainable development. These include such features as special constitutional provisions on environmental rights, Cabinet long- 
term sustainable development strategies, the designation of a specific body with cross-sectoral co-ordinating responsibilities, monitoring feedback reporting arrangements, as well as specific mechanisms for solving conflicts between ecological and sectoral objectives (see Lafferty 2001:14).

To provide a baseline for analysing the effectiveness and integration aspects of rational ecological governance, we can now formulate the following criteria:

- Ecological governance is effective in so far as 'ecological' values and norms, ecological capacities, and codes of ecologically good conduct are actually integrated into the political and administrative decision-making process of sectoral agencies and authorities.

- Ecological governance is integrated in so far as 'ecological concerns' are given specific weight or preference through political decisions at the highest level of authority, and when this is communicated and implemented into the political and administrative decision-making process of sectoral agencies and authorities.

\section{Providing the base for sectoral integration}

Early signs of policy co-ordination and sectoral environmental responsibility

A peculiar feature of the Swedish system of government is the division between 'political' ministries and 'administrative' agencies at the central level. The Cabinet and the Ministries in Sweden deal almost exclusively with policy formulation. The Cabinet, and thus the Ministry of Environment, has access to the constitutionally 'independent' national agencies and boards and their expertise when formulating new policies or revising old ones. The Cabinet as a collective, not the individual minister, issues implementation directives to these central agencies, but Ministers cannot decide on policy implementation, i.e., decisions on individual cases. This is, constitutionally, a matter for about 70 central national agencies, the nowadays 21 Regional Administrations, and the 289 local governments, the latter also enjoying a wide sphere of authority on local matters, such as taxation and physical planning. 
For more than two decades after the introduction of 'modern' environmental policy in the 1960 s, environmental issues were the preserve of the Ministry of Agriculture. As the major governmental agency for environmental affairs, the SEPA was given the mandate to protect the environmental 'sector interest' against that of other sectors. The major 1987/88 Environmental Bill spoke of a new strategy: 'A successful environmental management presupposes that care for the environment is integrated into the development plans for different sectors of society ... [who have] ... a responsibility to prevent new environmental damage' (Cabinet Bill 1987/88:85, p. 35 f.). The Ministry for Energy and Environment established in 1987 was to have 'an offensive and co-ordinating role within the Cabinet'; it should instil environmental aspects into other policy sectors, and thus also into other Cabinet Ministries (Cabinet Bill 1987/88:85, p. 28). Energy issues were brought back into the Ministry for Industry in 1990, when the Ministry of Environment took over issues of national physical planning from the Ministry of Housing and Physical Planning. The new Ministry of Environmental Affairs was strengthened to fill the role as co-ordinator of environment-related issues at the Cabinet level (Loftsson et al. 1993:71).

The 1990/91 Environmental Bill acted further on the integration theme. The Cabinet stated that the 'mission of the 1990s is to readjust all societal activities in an ecological direction'. To this end, the Cabinet now proposed that the future environmental policy should include increased sectoral responsibilities and decentralisation to secure broad support for environmental management, including individual, business, and municipal action as well as participation by public agencies and units in all sectors of society. A stronger emphasis must be put on evaluating the results of policy measures and instruments' (Cabinet Bill 1990/91:90, pp. 11, 13). The bill strengthened the environmental responsibilities of the national agencies for road, air and railway traffic, agriculture, fisheries, and forestry. Their charters would from then on require them to 'elaborate sectoral plans and programmes with precise environmental objectives to bring about the implementation of nationally determined goals in the most cost efficient way'. The central environmental agencies - SEPA and the Chemicals Inspectorate (Kemikalieinspektionen) - should provide information and knowledge to the sectoral agencies, and 
actively co-operate with them to formulate, follow up and evaluate sectoral action plans (Cabinet Bill 1990/91:90, p. 66).

The sectoral perspective thus began to recede around 1990. It now gave way to a view that environmental concerns should be integrated into other policy areas as a 'sectoral responsibility', explicitly including not just government - all sectoral agencies and all levels - but also private economic and social actors. However, such integration was still more of an aspiration than an actual, effective change. There was no clear-cut weighting of this environmental responsibility relative to other sectoral objectives. This is revealed in the 1991-94 Right-Centre Coalition Government's discussion on long-term sustainable development: 'Concern for the environment must influence decision-making at all levels and in all sectors of society. This means giving prior consideration to the environmental impact of every decision that might have a major impact on the environment.' (Cabinet Bill 1992/93:100, Part 15, p. 2). But what would such 'prior consideration' actually entail in relation to other policy objectives and impacts?

\section{'Common cause'? Integrating policy objectives for sustainable development}

It is evident that the issue of integration was brought to the fore even more intensely as a result of the commitments made by Sweden at the UNCED conference in 1992. Sustainable development in the sense discussed in the Brundtland report, and laid down in Rio, now emerged as the point of departure for bills across the political agenda. A first answer to the question of relative weight came with the 1993 decision on forestry policy; the objective of environmental quality should have equal weight to the earlier one of durable, effective and gainful production (Cabinet Bill 1992/93:226, p. 26).

However, the role of environmental and sustainability concerns varied a lot in the wave of cabinet bills that followed particularly in the parliamentary year 1997/98. Bills on transportation and consumer policy gave the clearest indication. Transportation policy objectives should be subordinate to other comprehensive societal goals. With respect to the environment, the Swedish transport system should be developed to 'promote good environmental and resource management' (Cabinet Bill 
1997/98:56, p. 16 f.). Long-term sustainable development should also have a clearer role in consumer policy. The Cabinet deemed it necessary to take action to give this objective the 'same weight as other objectives' in this field (Cabinet Communication 1997/98:67, p. 2 f.; italics mine).

Other policy statements were not as distinctive. In an earlier bill to change planning regulations, the Cabinet stated that planning is 'part of a coherent policy for sustainable development', and local physical planning should be 'successively developed towards increased attention to environmental concerns' (Cabinet Bill 1994/95:230, pp. 30, 45 ff.; italics mine). The culture policy bill stated that nature and culture are intimately linked. Therefore, the 'culture sector' must spread information about the cultural-natural heritage and 'actively participate in the public debate to promote sustainable development' (Cabinet Bill 1996/97:3, pp. 126 ff.; italics mine). The 1997 sustainable energy bill was hammered out after tough negotiations to secure a parliamentary majority. The bill stated that one objective of future energy policy would be to 'ease the transformation to an ecologically sustainable society', through increased energy efficiency and reliance on renewable energy sources (Cabinet Bill 1996/97:84, p. 7 f.; italics mine).

The bill on fisheries and agricultural policy contended that measures must be taken in 'all policy areas' to bring Sweden towards ecologically sustainable development. The formal 'sectoral responsibility' for central agencies means that they 'must actively work to decrease the environmental burdens' of their sectors and develop action plans for that purpose (Cabinet Bill 1997/98:2, pp. 5 ff.; italics mine). Both the 1992 UNCED and the 1996 Habitat conferences were seen as bringing new dimensions to housing policy. In addition to the historic 'social housing policy' objective, this policy should now 'create conditions' for sustainable development, including its ecological dimension. The LIP programme would be a major measure in this respect (Cabinet Bill 1997/98:119, pp. 38 ff.; italics mine. See above, p. 78).

A stream of governmental policy proposals in the latter part of the 1990s thus infused ecological values and norms into sectors of crucial importance to the fate of the environment. This incorporation of sustainable development as a policy objective in key 
sectors of society was, however, at the level of intentions. It was furthermore done with differing clarity and determination. The integration of 'sustainable development' in the hierarchy of sectoral policy objectives would thus have to be backed by common rules, procedures and denominators to create a truly integrated and effective ecological governance.

\section{'Common rules'; a new, comprehensive environmental code}

In the 1980s, it became increasingly evident that existing Swedish legislation concerned with environmental quality and the management of natural resources was insufficient to come to grips with the new generation of diffuse pollution problems. The challenges posed by the quest for sustainable development, and the joining of the EU further accentuated the need for an integrated body of law to regulate the society-nature relationship. The 1989 Environmental Protection Commission's report of 1993 proposed an amalgamation of more than a dozen environment-related laws into one single Environmental Code, intended to 'protect human beings, nature and the environment generally', where the latter included 'land, water, air, biological life and also human settlement'. The Commission recommended a shift from control of individual pollution sources to legally binding 'environmental quality standards', to be issued by the 'Government or an authority empowered by the Government' (SOU 1993:27, Part I, pp. 49, 52, 58). The Right-Centre coalition hurried its Code bill to parliament in August 1994 but lost the September election. The incoming Social Democrats recalled the Bourgeois bill and issued new directives to the now renamed Environmental Code Commission, who presented its final report in summer 1996. Just before Christmas 1997, the Social-Democratic Government finally sent its proposal for a new Environmental Code to Parliament, who passed the bill the following year.

The objective of the 1998 Environmental Code is to 'promote a sustainable development to ensure that present and future generations have a good and healthy environment.' (SFS 1998:808, $\$ 1$ ). The Code amalgamated no less than 15 different environment and natural resource-related Acts, and a special bill was passed to adjust all pertinent legislation to the Code (Cabinet Bill 1997/98:90). The Code contains 'general protection rules' with legally binding principles such as Polluters' Pay, Best 
Possible Technology, Least Harmful Product Substitution, and Least Harmful Location. There is also a Mandatory Duty to Collect Relevant Information and Knowledge before taking any action potentially dangerous to human health, natural resources and the environment (SFS 1998:808, Ch. 2). Legally binding Environmental Quality Standards are introduced, together with a further widening of the area of mandatory Environmental Impact Assessments. All this reflects the Government's emphasis on integration and internalisation of the sustainability objective into all walks of life (Cabinet Bill 1997/98:45, p. 201 ff.; SFS 1998:808, Chapters 5 and 6).

Seeing the Environmental Code as a means of 'inspiring those actors to think and act in such a way that they anticipate the mandatory rules of the Code' (Cabinet Bill 1997/98:45, p. 161), the Government presented motivations that hint at a particular view of integrated and effective ecological governance. The legal framework of the Code would build a platform for 'decentralised and preventive environmental measures' from which 'different actors - business, central and local administrations, associations, households and others - can formulate their environmental strategies'. The Government thus saw the Code as a central means to 'promote the development towards a sustainable society' (Cabinet Bill 1997/98:45, p. 170).

Even if the new legislation turns out to be successful in inspiring such anticipatory and environmentally favourable behaviour, there might still be conflicts of interest over the use and management of natural resources, and over the necessity to protect the environment. A crucial test of the Code's integrative strength is thus whether it contains rules giving specific weight to environmental concerns in crucial decisions. The Cabinet stated that the Code is 'not superior to other laws', and should be 'applied in parallel to other laws regulating such activities, measures, facilities and products covered by the Code but directed at other issues.' Insofar as there would be a conflict between the Code and other statutes and 'there is no prescription as to which rule should have precedence, such conflict should be resolved by applying general legal principles' (Cabinet Bill 1997/98:45, pp. 190 ff.; italics mine).

It is true that the Environmental Code incorporates some of the balancing sectoral perspective of the 1969 Environment Protection Act (SFS 1998:808, Ch. 2, \$7). There are, however, 
some priority rules. A balancing of economic and ecological aspects must never violate an environmental quality standard (see Gipperth 1999:176 f.). There is a stop rule; an activity can be stopped or legally prohibited if it is judged as a threat to human health or environmental quality. Only the Cabinet may issue an exemption from this rule (SFS 1998:808, Chapter 2, $\mathbb{S} \mathbb{S} 9-10)$. In the case of conflicts over the use of natural resources or areas deemed of 'national interest', priority should be given to such use(s) that are most compatible with the promotion of long-term sustainable management (SFS 1998:808, Chapter 3, $\mathbb{1 0}$ ).

\section{Making sectoral integration work}

'Common responsibility' for sustainable development; the greening of agencies' programme

Presenting his Social-Democratic Cabinet Policy Platform in March 1996, the new Prime Minister Göran Persson proclaimed the achievement of the 'ecologically sustainable society' as a new and 'noble' mission for Sweden's government. 'Environment must be an explicit and long-term priority', and Sweden should be 'an international driving force and a forerunner in the endeavours to create an ecologically sustainable development' (Parliamentary Record, March 22, 1996). That there was a determination to give ecological concerns greater emphasis was revealed in many ways in the months that followed. One sign was the swift change in content of the annual Cabinet Communication to the Parliament on the State of the Swedish Environment. Unlike earlier reports, the one from January 1997 (and those issued ever since) did not address individual environmental problems. Instead, it took as its point of departure the argument that the political objective of an ecologically sustainable society includes adjustments to both ecosystem capacities and socio-economic growth and welfare, and requires integration of 'environmental care and resource management ... into all processes in society'. The report contended that 'different societal sectors must assume an increased responsibility' in this respect (Cabinet Communication 1996/97:50, p. 4).

This shift in problem views was accompanied by changes in organisation. Internalisation and anticipation would be promoted not only through common causes in general policy statements and common rules of the Environmental Code. Sectoral agencies 
would have explicit responsibilities to address ecological concerns. The formation in January 1997 of the Delegation for Ecologically Sustainable Development (DESD) within the Cabinet was a core element in the Social-Democratic strategy. Consisting of the Ministers of Environment, Agriculture, Taxation, Basic Education, and the Junior Minister of Labour, this group's first, and explicitly short-term, assignment was to 'develop a platform for the Cabinet's comprehensive policy for an ecologically sustainable society.’ (Cf. Cabinet Bill 1997/98:150, Part 5).

Only two months later, in March 1997, the five Ministers presented their proposal for 'A Sustainable Sweden'. Defining sustainable development in terms of protection of the environment, efficient resource use, and secured long-term eco-system capacity, the Ministerial Delegation emphasised the inter-relatedness of economic, social and ecological aspects of sustainability. To 'create the conditions' for ecologically sustainable development, there must be political measures to encourage new behavioural patterns, and to select the most resource efficient policy alternatives. The system of governance needed would go far beyond that of environmental policy, involving all levels of government from the international to the local, as well as target groups and individual citizens.

The Delegation proposed a host of mechanisms for sectoral integration and internalisation of the sustainability objective. One concerned environmental objectives for all relevant sectors in society (see above, pp. 64-7 on the NEOs). Another would consist of a Greening of National Agencies Programme. This involved a common responsibility to organise for and carry out ecological sustainability assessments of all major agency actions, as well as a 'greening' of public purchase tenders. An elaborated system of Sustainable Development Reports based on commonly developed indicators should be set up to allow for environmental auditing of sectoral development (Cabinet Bill 1996/97:150, Part 5).

In this programme of greening public agencies, the Cabinet could build on already initiated changes. Its Environment Advisory Board reported in 1996 and 1997 on the sectoral integration of ecological concerns, recommending both a general and a specific environmental and sustainability responsibility for 
sectoral agencies (SOU 1996:112 and 1997:145). The general sectoral responsibility meant that the Director-Generals of all governmental agencies would now have to 'take into account' the demands on the agency activities following on not just from environmental policy, but from the objective of ecologically sustainable development (SFS 1995:1322, \7).

A 1998 Cabinet decision prescribed a specific sectoral responsibility for 24 national agencies. These agencies 'shall integrate environmental concerns and resource management in their activities and promote ecological sustainability within their sector' in line with the 'overarching objectives for ecologically sustainable development' (Cabinet Communication 1998/99:5, p. 13). First and foremost, sectoral agencies are required to identify their environmental roles in relation to their 'core' sectoral missions. They must furthermore assess how sectoral activities affect ecological aspects of sustainable development, and develop sectoral objectives and targets under the NEOs (see above, pp. 65-8). Some of them are specifically pointed out as 'responsible for the NEOs'; the SEPA accounts for eight of these objectives. Four central agencies are pointed out as particularly responsible for 'comprehensive' cross-sectoral NEO issues, connected to the environment, physical planning the cultural environment and human health (Cabinet Bill 2000/01:130, p. 226 f.).

All agencies and authorities covered by these aspects of sectoral responsibility for sustainable development are required to describe the socio-economic consequences of the objectives and targets to allow for cost-effective sectoral measures, and cooperate with sectoral actors as well as other agencies to promote sustainable development. Furthermore, they are expected to describe and evaluate progress and problems related to their ecological sector responsibility in their annual reports to the Cabinet (Cabinet Bill 1997/98:145, p. 173 f.). The SEPA and the National Audit Office were given mandates to develop generalised forms for such reports, which would contribute further to the internalisation of the agencies' ecological responsibilities (Cabinet Bill 1996/97:150, Part 5).

There has been a swift spread in the public sector of Environmental Management and Auditing Schemes (EMAS). This involves systematic environment-related work in accordance with 'greening' objectives and guidelines formulated in action plans, 
precise lines of environmental responsibility, as well as routines for monitoring and performance evaluation. The EMAS was introduced in 24 state agencies in 1997, and has been successively widened. By the end of 2001, nearly all of the totally 234 state agencies, authorities and administrative units ordered by the Government to introduce EMAS, were actually doing so (Cabinet Communications 1998/99:5, p. 12; 1999/2000:13, p. 10; 2000/01:38, p. 14; 2001/02:50, p. 17; see Table 5.1.).

Table 5.1 The Adoption and Development of Environmental Management and Auditing Schemes (EMAS) in Swedish National Governmental Agencies and Units 1997-2001

\begin{tabular}{lccccc}
\hline Year & 1997 & 1998 & 1999 & 2000 & 2001 \\
\hline $\begin{array}{l}\text { Swedish national govt. units } \\
\text { beginning EMAS work }\end{array}$ & 24 & 38 & 35 & 38 & 96 \\
\hline Cumulated number & 24 & 62 & 97 & 135 & 231 \\
\hline
\end{tabular}

Source: www.environ.se, as of 2001-11-19

It is interesting to note the Cabinet's expectations as to what this infusion of common ecological responsibility would entail. 'Sweden's long-term and systematic transformation work will prove that it is possible to find ways of integrating objectives of ecological sustainability into different policy areas and make them co-operate with the development within those areas' (Cabinet Communication 2000/01:38, p. 11). This integration is seen as a means for systematically steering the policies for sustainable development, as well as a means for decentralising ecological governance to the agencies and to relevant target groups and actors. This in turn will allow for anticipation of environmental effects at an early stage, leading to cost-effective preventive action. But for this to materialise there must be mechanisms for decision-making in cases of conflicting objectives of sectoral development and environmental quality. There are now regulatory and administrative mechanisms and incentives for bringing attention to such conflicts early on in the planning and decisionmaking process (Cabinet Communication 2001/02:50, p. 18). Still, however, the final and authoritative balancing of policy and sectoral objectives should come through the overarching 
budgetary and regulatory decisions by the Parliament and the Cabinet (Cabinet Bill 2000/01:130, p. 23).

'Common yardstick': a system of indicators to monitor (and evaluate?) sectoral ecological performance

It is one thing to 'encourage internalisation of environmental values among economic actors, i.e., make them feel responsible for the environmental impact of their action'. It is another to assess the progress towards environmental and sustainability objectives. This necessitates 'reliable data on the state of the environment' related to production and consumption processes in the different sectors as well as for society as a whole. And it implies the importance of 'making such information part of the standard operating procedures of sectoral agencies and ministries' (Jansen et al. 1998:294 ff.). The major alternatives discussed have been those of green indicators and State of the Environment reports integrating physical, economic and environmental data. There are at least three alternative types of indicators in use. First, there are descriptive indicators in line with the European Environmental Agency's work on indicators according to a Drivers-PressuresState-Impacts-Response (DPSIR) model (see SOU 1999:127, p. 27). Performance indicators compare actual conditions 'with a specific set of reference conditions'. Efficiency indicators aim at providing insight 'in terms of the efficiency of the resources used, the emissions and waste generated per unit of desired output' (Smeets and Weterings 1999:11 f., 14).

The process of developing the indicators followed two lines. In accordance with a 1997 Directive, the Cabinet's Environmental Advisory Board presented a series of proposals in 1998 and 1999 for a number of aggregated 'green' key indicators, eleven of which would be immediately put into use and six others projected for the not too distant future (see SOU 1998:170). This aggregate approach was influenced by the OECD work on indicators based on the Pressure-State-Response model (OECD 1993). The Board proposed aggregate green indicators as descriptive measures of pressure (the uses of energy, materials and chemicals), state (greenhouse effect, eutrophication, acidification, air quality in urban areas, and biological diversity), and response (environmentally adapted travel and transport, consumption, work processes, and changing nutrient cycles). As 'key' indicators they should, 
argued the Board, reflect ecologically strategic conditions. They should be measurable over long periods, and as far as possible be based on available data. Furthermore, they should provide for easy oversight, be few and easily understood by everyone. The 'key' indicators would thus provide a good base for public debate on sustainable development in Sweden (SOU 1999:127, pp. 7 f., $21 \mathrm{f}$.$) .$

At the same time, a Swedish system of indicators would also have to be detailed enough to allow for monitoring the progress towards the 15 National Environmental Objectives and the many interim targets and sectoral goals formulated to operationalise these NEOs. The green key indicators should therefore be linked with the system of 210 very detailed indicators for monitoring NEO progress worked out by the SEPA. This disaggregated SEPA system of indicators and measures was developed on the European DPSIR model (see SEPA 1999). The purpose is mainly descriptive, i.e., to follow the development and see whether, and at what pace, the NEOs are approached. If the level of aspiration were increased to include also to what extent actions taken to make progress towards the NEOs are cost-effective, even more detailed information would be necessary. This would be provided by continuously updated knowledge from research, environmental monitoring, special commission reports, official statistics, etc. (SEPA 1999).

The Environmental Objectives Commission reporting in the year 2000 followed the same line of reasoning. The Commission stated that green key indicators provide a good oversight of the progress towards a sustainable society. However, they might give a too simplified picture in view of the many and complex demands for information among different target groups. The Commission thus suggested a total of 159 indicators to follow-up and evaluate progress, and pointed out 25 agencies and units as responsible for one or several indicators at the central governmental level. Out of these 25, the eight agencies with 'main responsibility' for the 15 NEOs should co-ordinate monitoring and 'evaluate the effectiveness of policy measures and actions within their target sectors' (SOU 2000:52, Part 2, pp. 726 f., 732 f.).

However, the NEO system's complex web of structures and processes obviously necessitates some sort of co-ordinating hub to sort out the mass of data and provide guidance, oversight and 
continuous refinement and evaluation of progress measurement. The NEO Commission thus argued that the since the SEPA is already designated as having an overarching responsibility to coordinate the environmental policy field, this responsibility should be extended also to the monitoring and evaluation of progress towards 'Sustainable Sweden'. To this end, the Commission proposed the establishment of an Environmental Objectives Board (EOB) within the SEPA. This Board would be charged with co-ordinating monitoring and evaluation of NEO progress, pointing out and suggesting necessary changes in policy to improve goal attainment, and with identifying needs to improve monitoring and evaluation. Although closely connected to the SEPA, the new Objectives Board should report directly to the Cabinet (SOU 2000:52, Part 2, pp. 723 ff.).

In its NEO Bill to Parliament, the Cabinet argued for a somewhat smaller number of indicators to monitor progress. At the same time, the Cabinet clarified and extended the responsibilities of the Environmental Objectives Board. The Board is charged with effecting a co-ordinated and unified system of monitoring and reporting on the progress from all agencies and authorities under the NEO system. To this end the Board is to suggest NEO indicators as well as 'green key' indicators, and to provide monitoring and reporting guidelines to all responsible agencies and authorities. Most interesting is that the new Objectives Board is charged with the task of 'illuminating possible conflicts between the NEOs and other policy objectives set by the Parliament' (Cabinet Bill 2000/01:130, p. 229; italics mine). The composition of the Environmental Objectives Board appointed in December 2001 provides a hint of what the Cabinet included in its understanding of 'ecological governance'. Together with officers from the NEO agencies, there are representatives from other sectoral agencies, the Regional Administrations, local government, interest organisations and business (see www.environ.se). No doubt, the EOB's further work will be heavily influenced by the efforts to go beyond green 'key' indicators to provide a system of indicators covering all aspects of sustainable development. A first report on such an integrated system of indicators was published in May 2001 as part of Sweden's preparations for the Rio+10 conference in 2002 (SCB 2001). 
A 'common account': producing 'green' records and 'green' budgets for ecological governance

Clearly the agencies' responsibility to assess the ecological consequences of their own actions and the sector's development in general will push decision-makers to integrate environmental concerns. The same is true for the obligation to keep numerical tabs on ecological key aspects of agency actions and sectoral developments. Not the least will the EOB efforts to provide sectoral agencies with standardised ways of reporting on NEO developments force the agencies to elaborate their 'ecological routines'. The ultimate purpose of this whole exercise of monitoring the NEO process is to provide the basis for a conscious and continuous move towards what is here called ecological governance. However, it is evident from the many reports and bills on this subject that developing this basis is not solely a matter of measuring developments toward sustainability. It is also meant to provide decision-makers, targets groups and the general public with means for meaningful participation in the debate over governance, and thus to promote individual autonomy.

The 'key' indicators are obviously meant to meet the need for easily understood, yet very meaningful information about the state and trends of Sweden's ecology ('ecology' here interpreted in the same way as 'economy' in, e.g., State of the Economy reports). The more elaborate system of NEO indicators provides decisionmakers and sectoral interests with the means of assessing their actions. The NEO Commission proposed, and the Parliament confirmed, an elaborate system of reporting on the basis of indicators. Every year, the Cabinet is to provide Parliament with an account of how the NEO work progresses. This annual report is to be based on a selection of indicators, and is expected to give enough information for decisions to change or intensify action in areas where the process does not run on schedule (Cabinet Bill 2000/01:130, p. 230). There is already a tradition of how and when these reports are delivered to Parliament that reveals the degree of importance given to the indicators. Beginning in spring 1999, select green 'key' indicators are presented to Parliament in connection with the 'State of the Economy' reports and the Budget Bills (see Cabinet Communication 2000/01:38, p. 13).

However, even if monitoring and indicators are means to 
describe the direction, intensity and scope of change towards the goals of ecologically sustainable development in Sweden, this is not enough for meaningful political debate over ecological governance. There must also be some account that allows for evaluating whether the measures taken toward ecological sustainability are actually working and if so, whether and to what extent they are cost-effective or could be improved in that respect. This is achieved by integrating the descriptive indicator system based on data from environmental monitoring with economic and physical data to establish so-called environmental accounts (see EEA 1999). Following a 1992 Cabinet request, the National Institute for Economic Research (NIER, Konjunkturinstitutet) ran a fiveyear programme to develop monetary environmental accounts and environmental economic models to present and assess important connections between economy and environment in Sweden. The ultimate purpose is to systematise environmental and natural resource statistics and to integrate these data with economic statistics. In a parallel process, Statistics Sweden (SCB, Statistiska centralbyrain) has developed physical environmental accounts, i.e., a system of statistics where pressures on the environment and the use of physical natural resources are linked to economic statistical data on production and consumption (Konjunkturinstitutet 1998:3 f.).

By the end of the 1990s, these integrated National Environmental Accounts had been developed so far that they are in effect functioning as a 'satellite' to the National (Economy) Account. New areas are developed and included over time, such as the environmental impact of imported goods and services, environmental pressures from different categories of goods, water and forestry accounts, and the environmental impact of household behaviour (Cabinet Communication 2001/02:50, p. 27). The importance for environmental policy integration is shown by the fact that the 1999/2000 Commission on Sweden's Long-term Development extensively used environmental accounts to adjust the estimations of the prospects for long-term economic and social welfare sustainability in Sweden (SOU 2000:7, Ch. 5; see also Apps. 2 and 7). National environmental accounts also came to use in the proceedings of the Commissions on Climate and on NEOs (see SOU 2000:23, chs.12-13; SOU 2000:52, part 2, Chapters 24-25). The integrated economic and physical 
environmental accounts will - together with the elaborated system of descriptive indicators - provide the basis for the 'deeper evaluation' of progress towards ecologically sustainable development that the Cabinet is to present to Parliament every fourth year (Cabinet Bill 2000/01:130. p. 230).

\section{A 'common purse'; green procurement and green tenders throughout the public sector}

One of the major points in the spring 1997 report from the Cabinet's Delegation for Sustasinable Development concerned the possibilities of making the public sector a 'forerunner' towards sustainable development by utilising its position as a strong market actor. The size of governmental final consumption ranges between nine and 25 per cent of total GDP expenditures in the OECD countries (14 per cent in Sweden). An average of threequarters of public purchases are on current consumable goods and services. The greening of public procurement is viewed by the OECD as an innovative tool capable of providing cost-effective opportunities' and as having 'a crucial role in supporting innovation' of greener technologies and promoting greener production and consumption patterns (OECD 1999a:35; OECD1999b:4).

It goes without saying that the greening of public procurement and public tenders will also function as a strong mechanism for integrating environmental concerns into public agencies and authorities at all levels. Thus the Cabinet Delegation for Ecologically Sustainable Development recommended that the 1996 guidelines for 'environmentally adapted public procurement' developed by the SEPA and two other agencies should be successively updated by way of integrating experiences from the 'pilot' EMAS agencies as well as from local and regional levels and international developments (DESD 1997). The SocialDemocratic Government's Policy Platform of 2000 further emphasised the will to integrate 'environmental demands into all public procurement' (Cabinet Communication 2001/02:50, p. $18)$.

By then, the Cabinet's Committee for Ecologically Sustainable Procurement (CESP) had been working since early 1998. Its mandate up to the end of 2001 was to promote ecologically sustainable procurement throughout the public sector. A central concern is with effectiveness/efficiency; the Delegation should 
concentrate on such goods and services 'where the greatest benefits of applying requirements on ecologically sustainable development can be achieved'. Other parts of the CESP's mandate indicate that the development of green procurement routines is expected to promote integration of environmental concerns. The Committee should disseminate knowledge, experiences and best practice knowledge, initiate training programmes and seminars for purchasers, and not the least, develop a common, Internetbased instrument/guide for green procurement for the entire public sector. Through an extended mandate, the CESP should furthermore analyse the need for a special produrement policy for the entire public sector (CESP 2001:5 f.).

In its final September 2001 report, the Committee presented a new Internet-based instrument intended to help public sector organisations integrate environmental concerns into their procurement of goods, services and contracts'. This joint mechanism to be used throughout the entire public sector originally included environmental requirements and information for about 70 different product groups. The requirements range from mandatory demands over evaluation criteria to information on producer/seller qualifications (EMAS, ISO 14001 certifications), and eco-labelling of the goods or services in question. Upon delivering its report, the Committee pointed out that its integrative tool is quite far-reaching; the EU Commission's interpretative document issued in summer 2001 on environmental concerns in public procurement was more narrow. It meant that several of the Swedish CESP's requirements must be lifted out, reformulated and - perhaps - reintroduced at a later stage (CESP 2001:17, 45 ff., 62; see SOU 2001:31, pp. 176 ff.).

Furthermore, the Committee found a need for a more developed, common policy for green procurement in the public sector. Existing policies are usually too general to provide enough guidance. Not only the regulations in the Environmental Code, but also, and particularly, the demands stemming from the revised EU rules on eco-labelling and on EMAS necessitate a common policy. This should contain specifications of how the policy is integrated within the organisation, what role it is expected to play in achieving the objectives of green procurement, as well as how principles of precaution and substitutability are integrated in the policy. Naturally, procurement policies should also include 
the environmental requirements on sellers, goods and services, as well as mechanisms for monitoring and feedback on the greening of agency procurement (CESP 2001:53 f.). The government has yet (end of 2001) to act on the CESP's recommendations.

\section{Towards an effective and integrated organisation for ecologically sustainable development?}

\section{'An offer they can't resist'? The mix of instruments to bring about effective ecological governance}

It was stated at the outset of this chapter that there are two different but interrelated problems with respect to integrated ecological governance. The effectiveness/efficiency problem has to do with how to achieve greater environmental effectiveness through costeffective policy integration. The question is how to organise the structures and processes of governance so that ecological concerns are instilled into the workings of traditionally non-environmental sectoral policies and agencies in the most cost-effective way. This organisational aspect of environmental policy integration could be taken to include several measures. One concerns institutional structures to bring attention to issues of sustainability. Another is the conscious infusion into day-to-day decisionmaking processes of instruments that promote continuous attention to ecological concerns. Furthermore, there are strategies and means of monitoring ecological performance in terms of resources used and results achieved.

Quite clearly, the Swedish government has embarked on a conscious use of these strategies to promote an effective inclusion of environmental concerns at all stages and levels of governmental decision-making. It is also clear that these concerns have been widened to include the ecological aspects of sustainable development into the social, economic and cultural aspects traditionally pursued in the governance of the Swedish welfare state. Objectives related to ecologically sustainable development are explicitly inserted into all sectoral policies that have large actual and/or potential consequences for such development. All agencies, authorities and administrative units are now charged with a 'sectoral responsibility' for promoting ecologically sustainable development. Most of them experience this as a general duty on the leadership laid down in the General Agency Ordinance. 
However, as many as 24 agencies have a special sectoral responsibility for the environment, with more far-reaching demands on their performance.

The sectoral responsibility serves as a trigger to bring the authorities' attention to environmental and ecological constraints on, and effects of, their efforts to implement their traditional sectoral objectives. Their attention to these constraints and effects is furthermore triggered by the NEOs, since not only the ten agencies with particular NEO responsibilities, but also a host of other sectoral agencies are expected to play important roles in developing further sectoral and regional sub-goals and interim targets. Many of the acts regulating the use and management of natural resources for different sectoral purposes are linked to and coordinated with the Environmental Code. The principles contained in the Code (see above, pp. $126 \mathrm{f}$.) thus also relate to public sector actions potentially affecting environmental quality, as do the binding principles of good husbandry laid out in the Code. Agencies are also expected to carry out environmental impact assessments of their major actions. The sectoral responsibility also includes monitoring and evaluation of progress towards subgoals and interim targets. Furthermore, the policy for green public procurement forces all agencies to look hard at their routines and habits in terms of environmental standards, materials flows and resource efficiency. What all this means is that Swedish public agencies find themselves obliged to integrate environmental concerns throughout the decision-making process.

The massive introduction of EMAS into more than 200 agencies and units is evidently a measure designed to provide for effective environmental work throughout the public sector at the national and regional levels. As noted earlier, the SocialDemocratic Government has seen this tool as a way of decentralising ecological governance to the agencies, expecting that it will lead to early and effective action: 'EMAS promotes overview and efficiency in the work for ecologically sustainable development' (Cabinet Communication 2001/02:50, 18).

The reader may interject that such utterances by government are nothing but aspirations and expectations. Students of governance know that the implementation literature is replete with accounts of great political expectations becoming ruins of hope in the mazes of bureaucracy. Should we believe that all these 
integrative measures and schemes will actually become effectively enforced and implemented throughout the public sector in Sweden because of a favourable administrative culture? Or must central government use much stronger mechanisms to make sure that the different units effectively integrate environmental concerns into their outward sectoral as well as inward administrative actions? And, most critically, will these mechanisms actually come to function as expected?

As to the first question, it is reasonable to judge Swedish bureaucracy as effective in carrying out mandates and missions. A glance at the annual reports to government from the NEO agencies reveals that they have taken their NEO responsibility quite seriously. Just as an example, the National Board for Housing and Planning (NBHP, Boverket) tripled its use of resources to processes for refining the relationship between planning regulations and guidelines and the NEO at the turn of the century (NBHP 2001:18). The Chemicals Inspectorate states that its activities in the year 2000 was characterised by 'active anticipation' of implementing the 'Non-toxic Environment' NEO once it is passed by Parliament (www.kemi.se). The SEPA set up a special NEO Agency Group to support the co-operation among agencies with specific sectoral NEO responsibilities in 2001 (www.environ.se).

Jumping directly to the third question, it must be kept in mind that both the integration of ecological concerns into decisionmaking processes, and the continuous monitoring, evaluation and feedback of information with regard to progress, put new and quite strenuous burdens on the agencies. It may therefore take some time before the agencies can meet these demands. A report from the National Audit Office (NAO) examines agency work on the NEO 'No Eutrophication' in the five central agencies concerned with that objective, as well as the Regional Administrations. Its conclusions provide for some guarded pessimism. The feedback information is diverse, not well co-ordinated, and in some areas totally void of systematic statistical data (National Audit Office 2000:90). The information in the agencies' Annual Reports on their own environmental work is 'fragmented' and presented in very general (non-measurable) terms. Activities are not properly related to costs and effects, thus not allowing for assessments of the cost-effectiveness of environmental integration. The report concludes that more precise 
government demands for feedback information in the annual Letters of Regulation (regleringsbrev) issued to governmental agencies just before the beginning of the new fiscal year would have positive repercussions throughout the administrative system. Through conditions laid down in those Letters, more streamlined measurement and reporting on progress closely linked to inputs, and more of co-operation on monitoring could be achieved (National Audit Office 2000:47 ff., 89 f.).

The report just mentioned refers to agency work in 1997, i.e., before the final formulation of the 15 NEOs. This brings us back to the second question. Yes, central government does have measures at its disposal to make sure integration of ecological concerns into policy implementation is an offer that sectoral agencies cannot resist. The budget allocations provide a crucial means in this respect. In the Letters of Regulation just mentioned, Cabinet Ministries can put forth very specific objectives and detailed conditions for how the agencies should allocate their funds. The agencies are forced to account for how they spent their budget allocations, and whether and to what extent they achieved the objectives. This they should do in their demands for budget allocations in the following years as well as in the annual reports. Whether or not in response to the critical assessments of the National Audit Office, this tool is increasingly sharpened to make agencies and units respond to the demands for integration of environmental concerns. Thus the Letters of Regulation issued by the Environment Ministry in December 2001 contain a considerable number of specifications for what the NEO responsible agencies within its domain are expected to perform and deliver as feedback information on the progress and effectiveness of ecological integration (see http://miljo.regeringen.se/index.htm). This provides the Cabinet with possibilities to follow up on environmental integration and to make changes for further effectivisation of the process.

With regard to the effectiveness/efficiency dimension of policy integration, we may thus draw a two-pronged conclusion. Sweden's approach to ecological governance contains several means and mechanisms to make integration effective in so far as 'ecological' values and norms, ecological capacities, and codes of ecologically good conduct are consciously and continuously brought into the political and administrative decision-making 
process of sectoral agencies and authorities. At the same time, there are still problems with respect to the (measurement of the) efficiency of actual performance, as well as with respect to cooperation and co-ordination among responsible agencies in reporting on the progress of integration.

\section{Gaining weight? The role of ecology in integrated governance for sustainable development}

The most crucial question remains; are ecological concerns now fully integrated in Swedish policy-making, within as well as across sectors? In terms of the criteria for policy integration in general proposed by Underdal - (see above, p. 119) - there is inclusiveness in terms of space, time, actors and issues. All agencies in sectors with recognisable impacts on the environment, and indeed all other units of national government, have a statutory sectoral responsibility to take ecological concerns into account, and to evaluate their actions and performance in environmental terms. The NEO process means that this responsibility will have a long-term endurance and engage governmental units in 'ecological dialogue' with all relevant actors (see, e.g., SOU 2001:20, passim). This also means that the Swedish efforts towards environmental integration also fulfil one of Lafferty's criteria - (see above, p. 120) - for such integration. Environmental objectives are incorporated into all stages of policymaking in non-environmental policy sectors.

That leaves the criteria of aggregation and consistency. It was noted above that aggregation means that policies and policy measures are evaluated from some overarching criterion or principle, and that consistency connotes that the components of the policy are in agreement. As I have tried to show in earlier chapters, the Swedish government has increasingly emphasised that its pursuit of sustainable development also includes the ecological dimension. The 1996 policy platform of the Social-Democratic Cabinet assumed that goal conflicts among sectoral objectives could be resolved through strategies of ecological modernisation. By making 'green' an overarching criterion for economic and technological development, economic growth and socially and ecologically sustainable development could be brought into consistency with each other.

Much has been said about the shortcomings of ecological 
modernisation as a strategy for policy integration to achieve sustainable development (see, e.g., the overview in Carter 2001:211 ff.). As shown above, the Swedish Government's pursuit of this strategy seems to have been more of a short-term, stopgap measure to grab the political initiative on environmental issues. Some features of the LIP program implied that environmental objectives were indeed subsidiary - in overall political terms - to those in economic and labour market policies (see above, p. 78).

The NEO process and the agencies' sectoral responsibility for ecologically sustainable development go much further in meeting the aggregation and consistency criteria of policy integration. To paraphrase Lafferty, these central features in Sweden's ecological governance do in effect provide a 'basic mandate' for environmental and ecological concerns, politically determined by the Parliament and the Cabinet. They become comprehensive societal objectives, and the sectoral responsibility forces all units of government to analyse and take into account presumed environmental consequences in the overall evaluation of their decisions. As stated earlier, Lafferty argues that this is 'the essential difference between environmental policy integration and policy integration in general' (Lafferty 2001:10).

Still, we are left with the most fundamental question concerning environmental policy integration, i.e., that of its strength. The fact that sectoral agencies show signs of effective 'ecologisation' does not automatically mean that there is a political, intersectorally applied principle lending a privileged position to ecological concerns. Let us assume that the sectorally responsible agencies' analyses of some sectoral decisions find that there are contradictions between ecological concerns for the sustainability of life-support systems on the one hand, and traditional sectoral objectives on the other. What do the Cabinet and Parliament have to say about how such conflicts are to be resolved? In Lafferty's words, we ask whether there exists an explicit 'basic mandate for environmental privilege', i.e., a political commitment to minimise contradictions between environmental and sectoral policies by giving some recognised priority or strength to the former over the latter (Lafferty 2001:10; italics mine).

As we saw in the former section, central government - read the Cabinet - does use regulatory, economic and informative instru- 
ments to steer the sectoral agencies towards taking ecological concerns into account in their work. What we are looking for here is whether some of these measures also function as weighting devices. Quite clearly, the Letters of Regulation do exhibit such functions. The Cabinet (a) attaches ecological conditions to the agency budget allocations, (b) specifies certain environmental objectives to such sectoral policies as agriculture, forestry, transport, and housing and planning, and furthermore (c) demands specific feedback reporting on agency performance. This in effect means that central government gives specific weight to ecological concerns and values pertinent to sectoral policies.

The strong political backing for the NEO strategy and its generational perspective on ecologically sustainable development also implies the weight given to ecological concerns in the political and administrative decision-making. There are also some mechanisms for administrative co-ordination among the agencies with specific and/or NEO responsibilities of some importance here. The Environmental Objectives Board in operation since early 2002 is charged with developing and issuing guidelines for how all NEO-responsible agencies should monitor and evaluate progress towards the NEOs. The Board is also mandated to provide a comprehensive and co-ordinated annual NEO report to the Cabinet (www.environ.se).

Still, there will be conflicts between sectoral and environmental objectives. Expressions such as 'Sweden should continue to be a forerunner in the transformation to sustainable development' that includes not just economic and social but also ecological aspects which are 'interdependent and must be weighted in a balanced way' does not provide precise guidance as to how such conflicts are to be handled (Cabinet Communication 2001/02:50, p. 5). What then about the recent authoritative statement on Sweden's 'National Strategy for Sustainable Development', prepared for the Johannesburg meeting? One key passage is worth quoting at length:

The society of the future must be formed within the limits set by nature, environment and human health. To reach this long-term objective, economic growth, social consensus and environmental protection must be co-ordinated in a mutually enforcing manner. The strategy for sustainable development views the concern for environment as an important driving force for growth, development 
and employment. The transformation demands new solutions, new and environmentally friendly technology, environmentally adapted production of goods and services, new methods of transportation and new ways of producing energy. An active social policy, competitive business, and a stable economic growth are important building blocks for transforming Sweden into an ecologically, socially and economically sustainable society ... A renewed and long-term sustainable policy for welfare and social justice does not contradict economic growth, but is rather a condition for our long-term common welfare. (Cabinet Communication 2001/02:17)

Could this be read as 'a commitment to minimise contradictions between environmental and sectoral policies by giving priority to the former over the latter' (see Lafferty 2001: 10)? My answer is a tentative 'Yes'. We have seen earlier that statements from the Swedish Government indicate that the three aspects of sustainable development should be given equal weight in the efforts to transform Sweden into a sustainable society. What we find in the Swedish Johannesburg Report may well be seen as a further step forward. The first sentence of the quote explicitly places long-term social welfare and economic growth within the limits of nature. There is also an explicit view of environmental concern as a long-term driving force for social and economic development, and as a condition for long-term common welfare. Together with the statement that the three aspects of sustainable development should be managed in a mutually enforcing manner, one must conclude that, at least in principle, the Swedish Government places the ecological aspects of sustainable development at the centre. Temporally rational ecological governance recognises the limits of the commons, and co-ordinates all aspects of long-term sustainable development to protect the natural base of social welfare and economic growth.

As noted above, the Cabinet holds the view that in practice, the final and authoritative balancing of policy and sectoral objectives should come through the overarching budgetary and regulatory decisions by the Parliament and the Cabinet (Cabinet Bill 2000/01:130, p. 23). What remains to be seen is thus to what extent Parliament and the Cabinet are prepared to use their budgetary and regulatory powers to influence the final and authoritative weighting of environmental and sectoral objectives to keep environmental concerns at the centre of future resolutions 
of conflicts among societal objectives. The common yardsticks described earlier, and even more so the common accounts now introduced and used in the Cabinet's annual Finance Plan, do indeed provide means for enlightened political decisions.

There are thus clear attempts in Sweden to aggregate presumed ecological consequences into an overall evaluation of future policies, i.e., the common cause, the common yardstick, the common account. At the same time, we find remnants of ecological modernisation's win-win-assertions; policy-driven green technological change will provide important building blocks for 'Sustainable Sweden' and thus promote both economic growth and social welfare. For those acquainted with Sweden's political history since the 1930s, in particular the building of the social welfare state, this should come as no surprise. Even as a forerunner in the march towards an ecologically sustainable society, Sweden heads for the 'middle way'. 